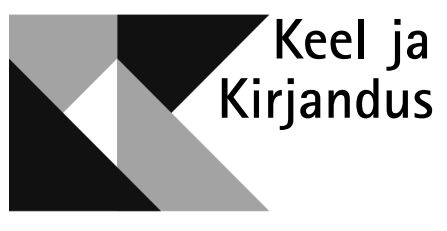

\title{
VALGUSTUSE POSTIHOBUSED
}

\section{Tõlkijad ja toimetajad enne ja nüüd}

\author{
TRIINU TAMM
}

$\mathrm{V}$ algustuse postihobusteks nimetas omal ajal tõlkijaid Puškin ja kohane on selline võrdlus kahtlemata ka siin ja praegu. Tõlkekirjandus on olnud eesti kultuuri ja keele ämmaemandaks ja käepikenduseks, ka meie kaasaegsesse kirjandusse annab ta algupärase loomingu kõrval mahult, kaalult ja loetavuselt igati võrdväärse panuse. Nagu on öelnud Ott Ojamaa (2010 [1969]: 63): „[T]õlkekirjandus pole originaalkirjanduse vaenlane ega hävitaja. Ta realiseerib ainult neid keeles peituvaid võimalusi, mida ükski eesti kirjanduse teos mitte kunagi ei realiseeriks. Rahuldab ainult neid vajadusi, mis muidu jääksid rahuldamata". Sellest tuleneb otseselt ja enesestmõistetavalt tõsiasi, mis küll laiemale üldsusele on sageli teadvustamata: kui suur on tõlkijate ja toimetajate roll ja vastutus eesti keele hoidjate ja koguni kujundajatena. Just võõrkeeles loodud teksti ümberpanemine võib nõuda emakeele piiride nihutamist, vahel koguni uute keelendite loomist, ning need ümberpandud tekstid on omakorda pinnaseks, mille peal on üles kasvanud ja kasvab edaspidigi nii eesti lugeja kui ka kirjanik.

Kuidas on viimaste aastakümnete jooksul muutunud tõlkekirjanduse väljaandmine, tõlkija ja toimetaja positsioon ja töötingimused ning milline võiks ideaalis olla tõlkija ja toimetaja roll ühe teksti sünni juures, sellele teemaderingile keskendus Eesti Kirjanike Liidu Tõlkijate Sektsiooni 2012. aasta oktoobris toimunud seminar, millega ühtlasi tähistati tõlkijate kaitsepühaku püha Hieronymuse päeva. Ettekannetega esinesid Anu Saluäär, Krista 
Kaer ja Tiiu Kokla, kellel kõigil on pikaajaline tõlkija- ja toimetajatöö kogemus, lisaks on nad kauaaegsed kirjastustöötajad ja oskasid tuua näiteid ka sellest valdkonnast. Tookord kõneldust on inspiratsiooni saanud ka käesolev kirjatükk.

Väliskirjanduse avaldamine nõukogude ajal oli teatavasti rangelt reguleeritud ja hoolega valvatud, ideoloogiliselt tundlik valdkond. Plaanimajanduse tingimustes ja võimaluste piires tegelesid tõlkekirjanduse väljaandmisega Eesti Riiklik Kirjastus, mis 1964. aastast kannab nime Eesti Raamat, ja ajakiri Loomingu Raamatukogu. Tõlkekirjanduse avaldamisel tuli silmas pidada kvoote ja n-ö lääne kirjandus pidi püsima kindlas proportsioonis vene ja vennasrahvaste omaga. ${ }^{1}$ Olid olemas keelatud autorite nimekirjad, et määnduv kodanlik dekadents nõukogude inimese mõtteid mürgitama ei pääseks, ja soositud autoritest, „meie meestest Havannas”2 (need nimekirjad aastate pikku muutusid), kuid igal juhul oli tõlkimise eeltingimuseks, et teos pidi vene keeles juba ilmunud olema. Kui 50-ndate lõpul - 60-ndate alguses hakkas poliitiline kontroll kirjastamistegevuse üle pisut leebuma, säilis siiski eel- ja järeltsensuur ning avaldamisplaanid tuli endiselt kinnitada Moskva Glavlitis. Selle kadalipu lühendamiseks loodigi 1957. aastal ajakirja Looming lisaväljaandena Loomingu Raamatukogu, mis formaalselt samuti ajakirjana allus leebematele reeglitele ja ainult kohalikule eeltsensuurile, mis kiirendas ja lihtsustas veidi kirjastamisprotsessi (1973. aastal meetmeid küll karmistati ja sestpeale pidi ka LR oma plaanid Moskvas kinnitama). Kirjastamisplaanid olid niisiis jäigad ja teave uudiskirjanduse kohta liikus vaevaliselt, ometi oli tõlkevalikute tegemisel oma roll ka tõlkijatel, kes olude kiuste püüdsid end kursis hoida tõlgitava keele kirjanduselus toimuvaga ja kes astusid kirjastusest läbi mitte ainult mõne poolelioleva töö asjus, vaid sellekski, et mõtteid vahetada. Nagu meenutab Henno Rajandi: „[Tõlkimist väärivate teoste] nimestiku kujundamine on tõlkija töö vahest kõige huvitavam, vaieldavam, vastutusrikkam osa, mõnes mõttes huvitavamgi kui teksti otsene ümberpanemine..." (tsit Sang 2002: 7). Koos riikliku vabadusega saabus trükija sõnavabadus, sellest ajast alates on Eestis tekkinud lausa müriaad kirjastamisega tegelevaid ettevõtteid, ${ }^{3}$ kellest terve hulk annab välja ka tõlkekirjandust. Piirangud ja kompromissid pole mõistagi kuhugi kadunud, need on lihtsalt teisenenud ja peamiselt majanduslikku laadi. Ka üleüldises infokülluses orienteerumine on ajamahukas ettevõtmine, kõige usinamgi kirjastaja ei suuda end kursis hoida terves maailmas toimuvaga. Kas tajuvad tänapäeva tõlkijad ja toimetajad seda vastutust, mis neil on oma lähtekeele kirjanduse soovitajate ja eestkõnelejatena? Et rahvusvaheliste menukite kõrval oleks võimalik eesti keeles lugeda ka uuenduslikku osa tänapäeva väärtkirjandusest, millele just nemad oskaksid tähelepanu juhtida, rääkimata visast osutamisest klassikalises kirjanduses valitsevatele tühimikele ja nende täitmisest.

1 1961-1970 olid Eestis trükitud raamatutest $40 \%$ algupärandid, $29 \%$ tõlgitud vene ja vennasrahvaste keelest, $31 \%$ ülejäänud keeltest. 1971-1980 olid vastavad numbrid $49 \%, 28,9 \%$ ja $22 \%$ ja 1981-1988 55,2 \%, $25 \%$ ja 20,4\%. Vt Möldre 2005: 180, tabel 8.

2 Nii kutsub Lembe Hiedel kapitalismimaade vasakpoolseid kirjanikke oma artiklisarjas „„Loomingu Raamatukogu” alaeast. Märkmeid ja meenutusi aastaist 1957-1973” (vt Hiedel 2006 [1995]). Need kirjutised annavad huvilisele üpris põhjaliku sissevaate tolleaegsesse kirjastamismaailma.

3 1992. aastal andis raamatuid välja 435 ettevõtet, 1997. aastal oli neid 606 ja 2000. aastal 638. Kaugeltki mitte neile kõigile pole kirjastamine peamine tegevusvaldkond. Kirjastusi, kes annavad välja rohkem kui kümme nimetust aastas, oli näiteks 1997. aastal 51. Vt Möldre 2005: 228. 
Kirjanduse tõlkimine võib olla kutsumus, ametialases mõttes on see aga olnud ja on praegugi hobilaadne tegevus, mida valdavalt harrastatakse n-ö leivatöö kõrvalt. Otsuse hakata vabakutseliseks langetavad tänapäeval vähesed. Honorarid, mis on püsinud aastaid muutumatuna, on vaieldamatult ebaproportsionaalsed töö hulgaga, mis on ühe hea tõlketeksti eelduseks. Lubatagu siinkohal väike merkantiilsest ajavaimust kantud arvutus. 2011. aasta IV kvartalis oli Eesti keskmine brutopalk 895 eurot kuus. Kui lähtuda niisama teoreetilisest keskmisest tõlkepoogna honorarist 115 eurot ja toimetamispoogna honorarist 35 eurot, saame, et keskmise palga väljateenimiseks peaks tõlkija kuus valmis saama 171 standardlehekülge puhast viimistletud proosatõlget ja toimetaja toimetama ja korrektuuri lugema 563 lehekülge. Tõsi, tänu stipendiumitele või kirjastuste küsitud toetustele tuleb teinekord ette helgemaid hetki. Aga ka siis pole kindel, kas tööd jätkub järgmiselgi kuul. Suhtes keskmise kuusissetulekuga olid nõukogudeaegsed honorarid oluliselt suuremad, tõlketasu varieerus Anu Saluääre sõnul seitsmekümnest (algaja puhul) saja rublani autoripoogna eest. Samal ajal oli tööpakkumisi vähem, kes aga oli endale juba nime teinud ja n-ö tsunfti pääsenud, võis päris hästi ära elada.

Keeletoimetaja ametiga see-eest nõukogude ajal hobi korras - erinevalt praegu üsna levinud praktikast - ei tegeldud, küll oli kõigis kirjastustes palgal suurem või väiksem toatäis toimetajaid ja korrektoreid. Maiga Variku sõnul pidi Eesti Raamatu toimetaja kuus toimetama kümme arvestuspoognat, Loomingu Raamatukogus toimetasid kaks toimetajat 140-150 poognat aastas (Hiedel 2006 [1995]: 166). Kas seda on palju või vähe, sõltub muidugi tõlke kvaliteedist, peab ka arvestama, et info hankimine ja kontrollimine oli toona oluliselt aeganõudvam; samas oli tagatud kuupalk ja kõrvalt võtta kolleege, kelle käest saada asjatundlikku nõu. Eesti Raamatus toimusid ka regulaarsed koosolekud, kus arutati keerukamaid juhtumeid ning lepiti kokku vormistuspõhimõtted. Loomingu Raamatukogus leidsid arutamised aset spontaansetel kellaaegadel ja teemadel, olid aga kahtlemata sama informatiivsed. Ning lisaks tõlkijale ja keeletoimetajale kandis teksti kvaliteedi eest hoolt korrektor või kaks. Eesti Raamatus näiteks istusid korrektorid kahekaupa laua taga ja lugesid kordamööda veerge, võrreldes neid käsikirjaga. Oleks naiivne arvata, et kõik tolleaegsed raamatud veatutena ilmusid, igati objektiivsetel põhjustel oli õigekirja- ja trükivigu aga tõesti vähe. Tänapäeval on koosseisulised toimetajad ja korrektorid luksus, mida lubavad endale vähesed kirjastused. Kõikuvate tootmismahtude ja trükiste mitmekesisuse juures poleks optimaalse lahenduse leidmine ilmselt ka kerge. Pädevatest toimetajatest on aga vahetpidamata puudus ja nii satub sellel alal kätt proovima hulk inimesi, kelle jaoks esimene koostöö kirjastusega jääb sageli viimaseks. Sellistes tingimustes on ilmuvate tekstide ühtlase, hea kvaliteedi tagamine tõepoolest keeruline, et mitte öelda võimatu. Teinekord hoitakse kokku korrektori pealt, kelle töö peab siis ära tegema toimetaja, mis pole sugugi ideaalne lahendus.

Ühtmoodi aktuaalne on läbi aegade olnud küsimus, kust leida häid tõlkijaid ning kuidas tagada väärt järelkasvu. Uno Liivaku sedastab 1975. aastal: „On aga üsna palju näiteid kutse-eetika nõuete eiramisest tõlkijate seas, piisavalt ka nende killas, kes on kutsutud ja seatud sel alal korda valvama. Selle tagajärjel on tõlkimine kujunenud lausa hõlptöö ehk haltuura sümboliks. Tõlkija nimetust nõudleb suur hulk inimesi, kes on tõlkeid tegema pääsenud oma ametiseisundit või tutvust ära kasutades" (Liivaku, Meriste 1975: 81). 
Heade tõlkijate vähesus ja mure järelkasvu pärast tuleb korduvalt jutuks ka mõned aastad hiljem ajalehe Sirp ja Vasar tõlkimise ja tõlkekirjanduse teemalises vestlusringis (Tõlkeraamat... 1978). Kui aga 1977. aastal ilmus Eestis 99 ilukirjanduslikku tõlketeost (sealsamas), siis näiteks 1991. aastal ilmus tõlkeraamatuid 191 nimetust (sh mitteilukirjandus) ja 2011. aastal 1073 nimetust (vahepealsetel aastatel veelgi rohkem, tipp oli 2008. aasta 1780 nimetusega) (Eestikeelsed raamatud...). Eesti rahvaarvu kõver osutab teatavasti teise suunda ja isegi kui humanitaarhariduse ja võõrkeelte omandamise tingimused on paranenud, pole paraku põhjust arvata, et suhtarvuna oleks kümnekordistunud inimeste hulk, kes viitsivad järjekindla töö ja enesetäiendamisega tõlkija ja toimetaja kutseoskusi lihvida. Tänapäeval on nii Tartu kui ka Tallinna Ülikoolis magistriastme õppekavasid, kus leidub ilukirjanduse tõlkimise mooduleid, Tallinna Ülikoolis on koguni olemas toimetaja magistriõpe. Kuid teadagi, teoreetiline ettevalmistus on alles esimene samm, järgmisi hädavajalikke samme teel tõlkija ja toimetaja ideaalide poole on võimalik astuda üksnes praktilise töö käigus. Nagu märgib Ott Ojamaa oma kõnes Henno Rajandi sünnipäeva puhul pärabarokki matkides: „Stsientistlikud elukubratsioonid, aju hallollusest aetud elaboraadid võivad olla, palehigine praktika peab olema" (Ojamaa 2002 [1988]: 199).

Mis puutub tõlkija ja toimetaja koostöösse, siis ilmselt ühendab kõiki tegevaid tõlkijaid rohkem või vähem ehmatav kogemus, mis saadud esimesest toimetatud tõlketööst. Samas on lausa hädavajalik, et algaja tõlkija sattuks kokku nõudliku ja asjatundliku toimetajaga. Algaja tõlkija ja kogenud toimetaja koostöö ja sõna otseses mõttes koos töötamine on asi, mida vanema põlve tõlkijad ikka hea sõnaga meenutavad ja millest tänase päeva nooremad tõlkijad kahtlemata puudust tunnevad. Eks olid toona teistsugused nii elukorraldus kui -tempo, kuid tundub, et ka väärtustati rohkem meistri-selli suhet ja „teatepulga edasiandmist”. Algajale tõlkijale on suur vahe, kas saada tagasi kirjuks parandatud paberipatakas või arvutifail, millega siis üksi omaenese tarkuses tõtt vaadata, või kogenud toimetajaga tema märkused ja ettepanekud ükshaaval läbi vaadata, saada selgitusi ja mõelda koos välja neid parimaid kolmandaid lahendusi.

Võrreldes varasemaga on kardinaalselt muutunud teabe kättesaadavus, igapäevaseks on muutunud otsekontaktid tõlgitava keele ja kultuuriga. Paranenud on teatmeteoste valik, ilmunud on „Eesti keele seletav sõnaraamat”, tõlke- ja oskussõnaraamatuid on täiendatud, välja on antud mõned uued. Kui aga vene-saksa-inglise keelde puutuv kõrvale jätta, on pilt sõnastike osas siiski jätkuvalt kesine, terve rea keelte osas on need nii pinnalised, et professionaalses tõlketöös neist abi pole, või puuduvad nad endiselt sootuks.

Kuigi tõlkija ja toimetaja töötingimused on niisiis viimase poole sajandiga üksjagu muutunud, mõnes lõigus avardumise, teises ahenemise suunas, on sisulises plaanis nõudmised ikka samaks jäänud. Ideaalne tõlkija peab valdama hästi nii võõrkeelt kui ka emakeelt, tundma lähtekeele kultuurikonteksti ja reaale, kahjuks ei tule laialdased teadmised üldse kõikidelt elualadelt, olulisteks omadusteks on arenenud seostamis-, kujutlus- ja kahtlusvõime. Uno Liivaku tõlkijaeetika peatükis ära toodud nõudmised: „Tõlkija ei asu töö kallale, millele hammas peale ei hakka” ja „Kunagi ei võta tõlkija ette rohkem tööd, kui ta jaksab ära teha" (Liivaku, Meriste 1975: 81) pole oma aktuaalsust minetanud praegugi. 
Kõike eelöeldut tuleb eeldada ka ideaalselt toimetajalt. Positiivseks nõukogude aja pärandiks tuleb pidada põhimõtet, et lisaks keelelisele kohendamisele võrdleb toimetaja tõlget originaaliga. Kahjuks pole see tänapäeval enam reegel, kuigi sellest tõusev kasu on vaieldamatu. Ka parimate kavatsuste ja suurte kogemustega tõlkijal tuleb ette inimlikke nõrkusi, nagu hajameelsus või väsimus, ja ükski inimene - kuigi ta ideaaltõlkijana muidugi peaks - ei saa teada kõike. Üsna üksmeelselt Eesti tõlkekultuuri kuldajastuks peetavatel 60-ndatel aastatel tõdeb Otto Samma (1962: 389): „Üheks tõlkimistaseme tõusu põhjuseks tuleb arvata seda, et tõlketeoste toimetajad on üldiselt palju kvalifitseeritum rahvas kui omal ajal.”

Tõlkija-toimetaja paarisrakendi omavahelises tööjaotuses on - jällegi ideaalis - tõlkija auasjaks valmistada ette tõlge, mille eest ta on valmis täielikult vastutama; toimetaja roll on osundav, täpsustav ja nõuandev, et parandamist saaks nii vähe kui võimalik ja nii palju kui vajalik. Nagu ütleb Anu Saluäär (2008 [1995]: 454): „[T]oimetaja peaks ideaalsel juhul olema nagu teatri- või muusikakriitik. Mitte varikirjutaja ehk ghostwriter, kes teeb verist vaeva nähes kehvast käsikirjast raamatu, mille tiitellehel ilutseb kehva tõlkija nimi." Eks elu teeb selles ideaalmudelis mõistagi üksjagu korrektiive.

Kindlasti on aga tervitatav selline variant, kui tõlkija ja toimetaja vaheldumisi mõlemat rolli kanda võtavad. Nagu märgib Ott Ojamaa (1972: 1913): „See [tõlkija ja toimetaja ühes isikus $-T$. T.] on väga sageli esinev kombinatsioon, vist isegi sagedasem, kui kirjaniku ja tõlkija oma, pealegi üpris elujõuline ja suure tööjõudlusega hübriid.” Kuigi tänapäevast võiks tuua näiteid ka kirjanik-tõlkijatest, kehtib tõdemus jätkuvalt: oma tõlke esimene toimetaja peab olema tõlkija ise, et originaali lummusest vabanenuna teksti kriitiliselt redigeerida, ja mida enam on tal selleks omandatud oskusi teisi toimetades, seda parem. Toimetaja jällegi võiks samuti mõnikord kogeda selle „õige ütlemise" leidmispiinu ja teinekord võimatustki, nagu ka tõlkijale osaks saavaid loojarõõme, et osata teiste tõlketööd hinnata ja vältida üleolekutunnet, mida pidev osutamine parimaski tõlkes ette tulevatele kahesilmavahelejäämistele või trükivigadele muidu kaasa võib tuua. Jääb ainult loota, et üldisel spetsialiseerumise ajastul siiski püsib elujõulisena ka see hübriidliik.

Uuel ajal kostab aeg-ajalt kurtmist, et tõlkekultuur on alla käinud ja ebakompetentsus lokkab. Tõsi, tõlgete maht on tohutult kasvanud, hea kõrval on paljunenud ka halb ning kiirustamise jälgi kohtab tõlkeraamatuteski. Teha aga sellest järeldusi tõlkekvaliteedi üleüldise allakäigu kohta või arvata, et uus aeg sünnitab üksnes pisikesi ja pimedaid vaime, on kindlasti ennatlik ja ülekohtune. Julgen arvata, et tõlkekirjanduse tänane paremik on vähemasti sama kõrgel tasemel kui „vanadel headel aegadel”. Kusjuures omaette ja sama hästi kui läbiuurimata teema on tsensuur nõukogudeaegsetes tõlgetes: mõnikord oli asi ideoloogiliselt sobimatus omadussõnas, teinekord aga lausa tervetes lõikudes ja peatükkides, mis tõlkes välja jäeti. Eks kipub ka nii olema, et rumal ja vigane riivab silma, head tõlget nauditakse - sageli raamatuarvustusteski - vaikimisi, ehk koguni kujutledes, et loetaksegi autorit ennast. Omaette teema on see, milline on tõlkija kui isiku suhe tõlgitavasse teksti. Kas nüüd just „tõlkija peab autoris surema” (Kask 1975: 1911) ja surra saabki, üsna üksmeelselt leitakse aga, et hea tõlge on selline, mis tõlkena silma ei paista, ning et tõlkija ei tohiks omaenda isikut ja sõnakasutust originaalile peale suruda. Põhjendamatu on samas see, kui tõlke läbipaistvuse nõue ori- 
ginaali suhtes kandub üle ka tõlkija isikule. Hea tõlkija jääb nii ilma õigusega välja teenitud tunnustusest, halb tõlkija vabaneb vastutusest. Tõlkija nime nihkumine tiitlipöördelt (nõukogudeaegne praktika) tiitellehele ja koguni raamatu kaanele on kindlasti tervitatav ning aitab loodetavasti kaasa tõlkija suuremale „nähtavusele”. Kahjuks tuleb aga endiselt ette, et tõlkeraamatu arvustustes tsiteeritakse autorit, samal ajal kui tõlkija nimi üldse puudub. Ja on olemas kirjastusi, kelle kodulehelt jääb mulje, et nende avaldatud autorid, näiteks Julio Cortázar, Irvine Welsh, Sandra Brown, Nora Roberts, Bertrand Meyer-Stabley ja Oksa Pollock kirjutavad kõik eesti keeles.

Ott Ojamaa (1972: 1911) on arvanud: „Ideaalne tõlkija peab ilmtingimata sündima nii, et tema parim loominguperiood langeks ajajärku, mil antud ühiskonnas tõlkekunst käib tõusuteed." Eeldused anda oma väärikas panus tõlkekirjandusse on tänasel päeval kahtlemata head, soovijal on võimalik kirjanduses toimuvaga pidevalt kursis olla, end keeleliselt ja igal muul viisil harida. Võimalused on avarad selleski mõttes, et tõlkekirjanduse järele on suur nõudmine, ning ehk ei olegi mõeldamatu, et tõlkija-toimetaja oma töö eest ka väärikamat rahalist tasu hakkab küsima. Lisaks sellele taevalikule tasule, mida pakub loomislust, võimalus viibida aina uutes mõtteilmades ja panustada vaimukultuuri üleilmsesse vereringesse.

\section{Kirjandus}

Eestikeelsed raamatud $\ldots=$ Eestikeelsed raamatud aastatel 1991-2011. Nimetuste arv. Allikas: Eesti Rahvusraamatukogu. http://www.nlib.ee/public/documents /Made/Eestikeelsed_raamatud_aastatel_1991-2011.pdf.

H i e d e l, Lembe 2006 [1995]. „Loomingu Raamatukogu” alaeast. Märkmeid ja meenutusi aastaist 1957-1973. - „Loomingu Raamatukogu” 50 aastat. Loomingu Raamatukogu, nr 37-40, lk 159-204.

K a s k, Leili-Maria 1975. Tõlkimisest. - Looming, nr 11, lk 1910-1914.

L i i va k u, Uno, M e r is te, Henno 1975. Kuidas seda tõlkida. Tallinn: Valgus.

M öld r e, Aile 2005. Kirjastustegevus ja raamatulevi Eestis 1940-2000. Tallinn: Tallinna Ülikooli Kirjastus.

Oj a m a a, Ott 1972. Arutlus ideaalsest tõlkijast. Otto Samma kuuekümnendaks sünnipäevaks. - Looming, nr 11, lk 1909-1918.

O j a m a a, Ott 2002 [1988]. Henno Rajandi klassikuks saamine. - Henno Rajandi, Tõlkija teekond. Koost Marek Tamm. (Eesti mõttelugu 48.) Tartu: Ilmamaa, lk 195-200.

O j a m a a, Ott 2010 [1969]. Kümnenda muusa muresid I. - Armastus seaduslikus abielus. (Eesti mõttelugu 92.) Tartu: Ilmamaa.

$\mathrm{S}$ a $l$ u ä ä r, Anu 2008 [1995]. Who cares? Toimetaja kui teatrikriitik või kui tarbijakaitsja? - Põhjamaadest ja Eestist. Kirjutisi 1987-2008. Tallinn: Eesti Keele Sihtasutus, lk 454-456.

S a m m a, Otto 1962. Üht-teist tõlkimisest ja tõlkijatest. - Keel ja Kirjandus, $\mathrm{nr}$, lk 385-392.

S a n g, Joel 2002. Vaba vaim. - Henno Rajandi, Tõlkija teekond. Koost Marek Tamm. (Eesti mõttelugu 48.) Tartu: Ilmamaa, lk 7-10.

Tõlkeraamat... 1978 = Tõlkeraamat ja tõlkija kirjandus(elu)pildis. - Sirp ja Vasar 1978, nr 11. 